\title{
Expression of annexin A1 in Leishmania-infected skin and its correlation with histopathological features
}

\author{
Helen Aguiar Lemes da Silva ${ }^{[1]}$, Gabriel Silva de Lima ${ }^{[2]}$, Mariana Côrtes Boité ${ }^{[3]}$, \\ Renato Porrozzi ${ }^{[3]}$, Marcia Hueb ${ }^{[4]}$ and Amilcar Sabino Damazo ${ }^{[1],[5]}$
}

[1]. Pós-Graduação em Ciências da Saúde, Laboratório de Histologia, Universidade Federal de Mato Grosso, Cuiabá, Mato Grosso, Brazil. [2]. Laboratório de Histologia, Faculdade de Medicina, Universidade Federal de Mato Grosso, Cuiabá, Mato Grosso, Brazil. [3]. Laboratório de Pesquisa em Leishmaniose, Coleção de Leishmania, Instituto Oswaldo Cruz, Rio de Janeiro, Brazil. [4]. Hospital Universitário Julio Müller, Faculdade de Medicina, Universidade Federal de Mato Grosso, Cuiabá, Mato Grosso, Brazil. [5]. Laboratório de Histologia, Faculdade de Medicina, Universidade Federal de Mato Grosso, Cuiabá, Mato Grosso, Brazil.

\begin{abstract}
Introduction: The aim of this study was quantify annexin A1 expression in macrophages and cluster of differentiation 4 (CD4)+ and cluster of differentiation $8(\mathrm{CD} 8)+$ T cells from the skin of patients with cutaneous leishmaniasis $(\mathrm{n}=55)$ and correlate with histopathological aspects. Methods: Infecting species were identified by polymerase chain reaction-restriction fragment length polymorphism, and expression of annexin A1 was analyzed by immunofluorescence. Results: All patients $(\mathrm{n}=55)$ were infected with Leishmania braziliensis. Annexin A1 was expressed more abundantly in $\mathrm{CD}_{163}{ }^{+}$macrophages in infected skin $(\mathrm{p}<0.0001)$ than in uninfected skin. In addition, macrophages in necrotic exudative reaction lesions expressed annexin A1 at higher levels than those observed in granulomatous $(\mathrm{p}<0.01)$ and cellular lesions $\mathrm{p}<0.05)$. This difference might be due to the need to clear both parasites and necrotic tissue from necrotic lesions. $\mathrm{CD}^{+}$cells in cellular lesions expressed annexin A1 more abundantly than did those in necrotic $(\mathrm{p}<0.05)$ and granulomatous lesions $(\mathrm{p}<0.01)$. Expression in $\mathrm{CD} 8^{+} \mathrm{T}$ cells followed the same trend. These differences might be due to the pervasiveness of lymphohistiocytic and plasmacytic infiltrate in cellular lesions. Conclusions: Annexin A1 is differentially expressed in $\mathrm{CD}_{163}$ macrophages and $\mathrm{T}$ cells depending on the histopathological features of Leishmania-infected skin, which might affect cell activation.
\end{abstract}

Keywords: Cutaneous leishmaniasis. Annexin A1. Lymphocytes. Macrophages.

\section{INTRODUCTION}

American cutaneous leishmaniasis is a non-contagious infection of the skin and mucosa by parasitic protozoans of the genus Leishmania ${ }^{(1)(2)(3)}$. It is transmitted through female Phlebotomus and Lutzomyia sand flies ${ }^{(4)}$. The infection is diagnosed based on a compendium of clinical, epidemiological, and laboratory characteristics ${ }^{(2)}$.

The host immunological response determines to a significant extent whether the infection persists or is cleared has high relevance for determining cure or persistence ${ }^{(5)(6)}$. In early infection, no macroscopic pathological changes occur in the epidermis ${ }^{(7)}$. Following initial acute inflammation, the infection progresses to a silent phase lasting a few weeks to months, during which the parasite proliferates without clinical manifestation. The silent phase ends with extensive inflammation

Corresponding author: Prof. Amilcar Sabino Damazo. Departamento de Ciências Básicas em Saúde/FM/UFMT. Av. Fernando Correa da Costa 2367, 78060-900 Cuiabá, Mato Grosso, Brasil.

Phone: 5565 3615-6233; Mobile: 5565 9211-2178

e-mail: damazoas@pq.cnpq.br; asdamazo@yahoo.com.br

Received 3 June 2015

Accepted 26 August 2015 and lesion formation at the infection site ${ }^{(8)}$. Lesion healing and parasite clearance correlate with a preponderance of chronic rather than acute inflammatory cells in the infected tissue ${ }^{(9)}$. However, while a $\mathrm{T}$ cell-mediated response is essential to clear parasites in most cases ${ }^{(10)}$, the dogma Th1 $=\mathrm{good} / \mathrm{Th} 2=$ bad is somewhat inadequate ${ }^{(11)}$. For instance, hyperinflammatory collateral damage from Thelper type 1 (Th1) response has been reported, along with a variable Thelper type 2 (Th2) response dependent on cytokine release and other T cells ${ }^{(12)(13)}$. Moreover, Cardoso et al. ${ }^{(14)}$ demonstrated that cluster of differentiation $8(\mathrm{CD} 8)^{+} \mathrm{T}$ cells in patients with subclinical Leishmania braziliensis infection secrete interferon gamma (IFN- $\gamma$ ) to activate macrophages and facilitate parasite clearance. Notably, Pereira-Carvalho et al. ${ }^{(15)}$ showed that $\mathrm{T}$ cells maintain activation levels at approximately 2 years after the end of therapy, and lymphocytes from well-healed lesions recognize leishmanial stimuli and proliferate upon exposure. Taken together, the data indicate that the immune response against Leishmania is very complex, and it is essential to understand better the processes at the infection site and the molecules present at inflammation site. Annexin A1 (ANXA1), also known as lipocortin-1, is a $37-\mathrm{kDa}$ calcium- and phospholipid-binding protein involved in several biological processes, including suppression of inflammation $^{(16)(17)(18)}$. Indeed, ANXA1 modulates leukocyte extravasation to the site of inflammation and regulates cytokine release in acute, chronic, or systemic inflammation ${ }^{(19)(20)}$. 
Its role in adaptive immunity is poorly understood; however, it has been shown to inhibit proliferation and differentiation of $\mathrm{T}$ cells by modulating $\mathrm{T}$ cell receptor signaling ${ }^{(18)}$. To help define the role of ANXA1 in adaptive immunity, we analyzed its expression in $\mathrm{CD} 63^{+}$macrophages, $\mathrm{CD} 4^{+}$, and $\mathrm{CD} 8^{+} \mathrm{T}$ cells from skin biopsies of patients with cutaneous leishmaniasis, and investigated its correlation with histopathological features. This study is important for shows the relevance of ANXA1 dynamics in the immune system regulation during cutaneous leishmaniasis.

\section{METHODS}

\section{Patients}

This cross-sectional study was performed in 55 patients with symptomatic cutaneous leishmaniasis who were treated at Julio Müller University Hospital [Hospital Universitário Julio Müller (HUJM)], Cuiabá, State of Mato Grosso, Brazil, between February 2012 and November 2013. Patients were of both sexes, aged 18-80 years. Patients who presented other infectious or immunosuppressive diseases, as well as those who were already being treated for leishmaniasis were excluded. Twenty patients undergoing surgery for colorectal cancer were used as control, and skin biopsies were collected at the incision site.

The Ambulatory of American Tegumentary Leishmaniasis/ HUJM is used in the State of Mato Grosso to diagnose and treat leishmaniasis. To confirm infection, patients received clinical examination, as well as histopathological and parasitological tests suggestive of Leishmania infection, including blades from aspirate, shave, and smear of injured tissue, as well as cultures from aspirate and biopsy of the lesion. Following diagnosis, infecting species were identified by polymerase chain reactionrestriction fragment length polymorphism (PCR-RFLP).

\section{Histopathology}

Patient received local anesthesia and lesions were previously disinfected. Tissue samples were obtained by biopsy with a 4-mm punch. Tissues were then immersed in $10 \%$ formol, dehydrated through a gradient of crescent alcohol, clarified in xylene, and embedded in paraffin. Samples were sectioned at $3 \mu \mathrm{m}$ by using a HYRAX M60 microtome (Carl Zeiss, Germany), deparaffinized in xylene, hydrated in decreasing concentrations of alcohol, and stained with hematoxylin-eosin. Lesions were then scored by pathologists who were blinded to the study according to the criteria defined by Magalhães ${ }^{(21)}$ for cellular exudative reaction (CER), granulomatous exudative reaction (GER), necrotic exudative reaction (NER), granulomatous-necrotic exudative reaction (GNER), and tuberculoid exudative reaction (TER).

\section{ANXA1 expression}

Histological sections were fixed on slides with a biological adhesive, deparaffinized with xylene, hydrated in decreasing concentrations of alcohol, and incubated for $1 \mathrm{~h}$ in $0.21 \%$ sodium citrate $\mathrm{pH} 6.0$ set at $70^{\circ} \mathrm{C}$. Samples were then treated for 30 min with $3 \%$ hydrogen peroxide in $70 \%$ methanol to block endogenous peroxidase, permeabilized in $0.4 \%$ Tween 20 in phosphate buffer saline for $15 \mathrm{~min}$, and blocked for $30 \mathrm{~min}$ with
5\% bovine serum albumin (Sigma-Aldrich, Rio de Janeiro, Brazil) in phosphate buffered saline (PBS). Sections were then probed with rabbit anti-ANXA1 (Invitrogen, USA; 1:200), and labeled for $1 \mathrm{~h}$ at $25^{\circ} \mathrm{C}$ in a humidified chamber with secondary goat antirabbit immunoglobulin $\mathrm{G}(\mathrm{IgG})$ conjugated to Alexa Fluor 488 (Invitrogen, Eugene, OR, USA; 1:50). Antibodies were diluted in $1 \%$ bovine serum albumin (BSA) in phosphate buffered saline (PBS). Sections were also stained with the nuclear fluorescent dye 4',6-diamidino-2-phenylindole (Sigma, USA) to facilitate morphological characterization. Finally, slides were washed in PBS, mounted in 1:1 glycerin: PBS, and examined under an AxioScope.A1 microscope (Carl Zeiss, Germany).

We quantified ANXA1 expression in AxioVision (v.4.8.1, 2009), using median optical density in arbitrary units (AU) (scale values: 0 to 255). For densitometry, images were obtained with a $20 \times$ objective lens, and readings are reported as mean \pm SEM. ANXA1 expression was analyzed in the cytoplasm of $\mathrm{CD}_{163^{+}}$macrophages, $\mathrm{CD} 4^{+}$, and $\mathrm{CD} 8^{+} \mathrm{T}$ cells $(\mathrm{n}=10$ cells types per each patient).

\section{Identification of $\mathrm{CD} 163^{+}$monocytes, $\mathrm{CD4}^{+}$and $\mathrm{CD8}^{+} \mathrm{T}$ cells and Leishmania parasites}

To identify host and parasite cells, sections were probed for $18 \mathrm{~h}$ at $4^{\circ} \mathrm{C}$ in a humidified chamber with mouse primary antibodies against CD4 (Invitrogen, USA; clone RPA-T4, 1:100), CD8 (BD Biosciences, USA; clone RPA-T8, 1:100), CD163 (Cell Marque, USA; clone EP152, 1:200), and Leishmania (Invitrogen, USA; 1:300). Subsequently, samples were labeled for $1 \mathrm{~h}$ at $25^{\circ} \mathrm{C}$ in a humidified chamber with secondary goat anti-mouse antibody conjugated to Alexa Fluor 546 (Invitrogen, Eugene, OR, USA; 1:50). All antibodies were diluted in $1 \%$ BSA in PBS. Sections were also stained with the nuclear fluorescent dye 4',6-diamidino-2-phenylindole (Sigma, USA) as described. Host and parasite cells were identified using morphometric tools in AxioVision (v.4.8.1, 2009).

\section{DNA extraction from skin biopsies}

Deoxyribonucleic acid (DNA) was extracted using Wizard ${ }^{\mathrm{TM}}$ Genomic DNA Purification kit (Promega, WI, USA) from skin biopsies frozen and stored at $-80^{\circ} \mathrm{C}$. DNA was quantified using NanoDrop®.

\section{Identification of infecting Leishmania species}

Internal transcribed spacer 1 (ITS1) ribosomal deoxyribonucleic acid (rDNA) ${ }^{(22)}$ was amplified in $50-\mu \mathrm{L}$ PCR reactions containing $4 \mu \mathrm{L}$ DNA extract, $200 \mu \mathrm{M}$ dNTPs, $1.5 \mathrm{mM}$ $\mathrm{MgCl}, 1 \mathrm{U}$ GoTaq ${ }_{\circledast}$ DNA polymerase (Promega, USA), and 20 pmol each of forward primer with sequence 5'-ctg gat cat ttt ccg atg-3' and reverse primer with sequence 5 '-tga tac cac tta tcg cac tt-3'. Reactions were denatured at $94{ }^{\circ} \mathrm{C}$ for $5 \mathrm{~min}$, and amplified over 30 cycles at $94^{\circ} \mathrm{C}$ for $30 \mathrm{~s}, 61^{\circ} \mathrm{C}$ for $1 \mathrm{~min}$, and $72^{\circ} \mathrm{C}$ for $1 \mathrm{~min}$, followed by final extension at $72^{\circ} \mathrm{C}$ for $10 \mathrm{~min}$. Amplification products $(11 \mu \mathrm{L})$ were digested at $65^{\circ} \mathrm{C}$ for 20 min with $1 \mu \mathrm{L}$ Sau $3 \mathrm{AI}$ in $5 \mu \mathrm{L}$ cutSmart buffer and $33 \mu \mathrm{L}$ distilled water. Restriction products were electrophoresed and visualized by silver staining using a GenePhor electrophoresis unit (GE Healthcare) and a high-resolution $12.5 \%$ polyacrylamide gel 
kit (GeneGel Excel 12.5/24 kit, GE Healthcare). Reference species and reactions without template DNA were used as controls, in accordance with World Health Organization (WHO) standards. The reference species L. braziliensis (MHOM/BR/1975/M2903/ IOC/L566), L. amazonenses (IFLA/BR/1967/PH8/IOC/L575), L. lainsoni (MHOM/BR/1981/M6426/IOC/L1023), L. naiffi (MDAS/BR/1979/M553/IOC/L1365), and L. shawi (MCEB/ BR/1984/M8408/IOC/L1545) were kindly provided by the Leishmania Collection of the Instituto Oswaldo Cruz, Instituto Oswaldo Cruz/Fundação Oswaldo Cruz (IOC/FIOCRUZ).

\section{Statistical analyses}

We compared ANXA1 expression using one-way analysis of variance (ANOVA) and Bonferroni's post-hoc test in GraphPad Prism v. 5.01 for Windows (La Jolla, CA, USA); Values were considered significant and displayed as symbols in the figures as: one symbol, $\mathrm{p}$ value below 0.05 ; two symbols, $\mathrm{p}$ value below 0.01 ; three symbols, $\mathrm{p}$ value below 0.001 .

\section{Ethical considerations}

Participation was voluntary, and patients signed informed consent forms of their own cognizance. This study was approved by the Research Ethical Committee of Julio Müller University Hospital (625-CEP-HUJM/2009).

\section{RESULTS}

\section{Identification of infecting Leishmania species}

The infecting species in all 55 cases was identified by PCRRFLP to be Leishmania braziliensis (Figure 1).

\section{Histopathological analysis}

Nine (16.3\%) patients were women, and $46(83.7 \%)$ were men. Patients were 18-72 years old, with mean age 38 years. All patients presented skin lesions, which were scored cellular $(\mathrm{n}=25 ; 45.5 \%)$, necrotic $(\mathrm{n}=9 ; 16.3 \%)$, and granulomatous exudative reactions $(\mathrm{n}=21 ; 38.2 \%)$. Tissue samples tested positive for Leishmania by immunofluorescence (Figure 2).

\section{ANXA1 expression}

Expression of ANXA1 in macrophages and T cells recruited to leishmaniasis lesions was measured by immunofluorescence (Figure 3 and Figure 4). $\mathrm{CD}_{163^{+}}$macrophages expressed ANXA1 at basal levels in uninfected individuals. However, $\mathrm{CD}_{163}{ }^{+}$macrophages in infected lesions expressed ANXA1 more abundantly $(107.0 \pm 2.7 \mathrm{AU}$ versus $64.6 \pm 3.0 \mathrm{AU}$ in uninfected control, p < 0.0001) (Figures 3A-H), even though expression did not correlate with age of the lesion $\left(r^{2}=0.0031\right.$, Figure 3I). Expression was higher in necrotic lesions $(123.5 \pm 6.9 \mathrm{AU})$ than in granulomatous $(100.0 \pm 4.1 \mathrm{AU}$, $\mathrm{p}<0.01)$ and cellular lesions $(104.6 \pm 3.0 \mathrm{AU}, \mathrm{p}<0.05)$ (Figure 3H). Expression did not correlate as well with time of lesion, with $\mathrm{r}^{2} 0.0462,0.2403$, and 0.1735 for granulomatous, cellular, and necrotic lesions, respectively. In all cases, ANXA1 was expressed in the cytosol and cell membrane (Figure 3B and Figure E).

ANXA1 was also mainly expressed in the cytoplasm of $\mathrm{CD}^{+}$and $\mathrm{CD}^{+} \mathrm{T}$ cells (Figures $\mathbf{4 A - F}$ ). Expression in $\mathrm{CD} 8^{+}$ cells was higher in cellular lesions $(121.3 \pm 9.0 \mathrm{U})$ than in granulomatous $(76.0 \pm 11.4 \mathrm{AU}, \mathrm{p}<0.05)$ and necrotic lesions $(77.0 \pm 10.4 \mathrm{AU}, \mathrm{p}<0.05)$. Similarly, expression in $\mathrm{CD}^{+}$cells was higher in cellular $(123.9 \pm 11.6 \mathrm{AU})$ than in granulomatous $(87.7 \pm 5.2 \mathrm{AU}, \mathrm{p}<0.05)$ and necrotic lesions $(53.7 \pm 15.7 \mathrm{AU}$, $\mathrm{p}<0.01$ ) (Figure 4G and Figure $\mathrm{H}$ ). As in $\mathrm{CD}_{163}{ }^{+}$macrophages, expression in $\mathrm{CD}^{+}$and $\mathrm{CD} 4^{+} \mathrm{T}$ cells did not correlate with age of the lesion, with $\mathrm{r}^{2} 0.0267$ and 0.00488 , respectively (Figure 4I and Figure J). Accordingly, expression did not correlate with age of specific lesions, with $\mathrm{r}^{2} 0.0274,0.0213$, and 0.1011 for $\mathrm{CD} 8^{+} \mathrm{T}$ cells in granulomatous, cellular, and, necrotic lesions, respectively, and $0.04981,0.0024$, and 0.0859 for $\mathrm{CD}^{+} \mathrm{T}$ cells.

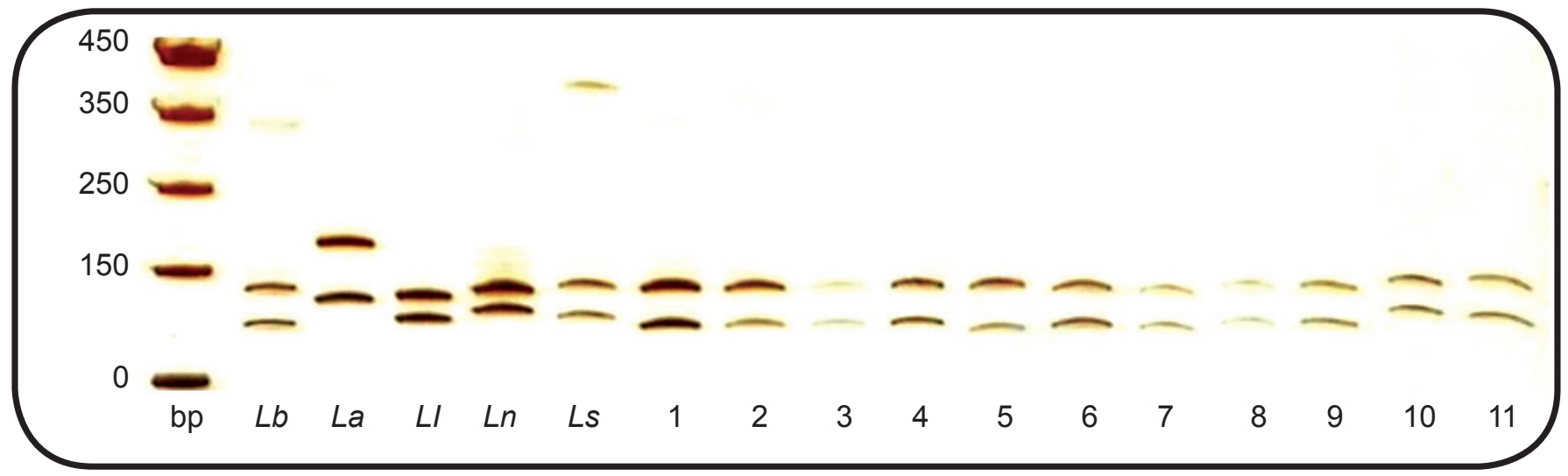

FIGURE 1 - Identification of the infecting Leishmania species by PCR-RFLP. Representative silver-stained 12.5\% polyacrylamide gel (GenePhor ${ }^{\circledR}$ ) of RFLP patterns generated by digesting PCR-amplified ITS1 rDNA with Sau3AI. bp: 100-bp molecular weight marker; Lb: Leishmania braziliensis; La: Leishmania amazonensis; Ll: Leishmania lainsoni; Ln: Leishmania naiff; Ls: Leishmania shawi; numbers 1 to 11: representative samples from patients with cutaneous leishmaniasis; PCR-RFLP: polymerase chain reaction-restriction fragment length polymorphism; ITS1: internal transcribed spacer 1; rDNA: ribosomal deoxyribonucleic acid. 


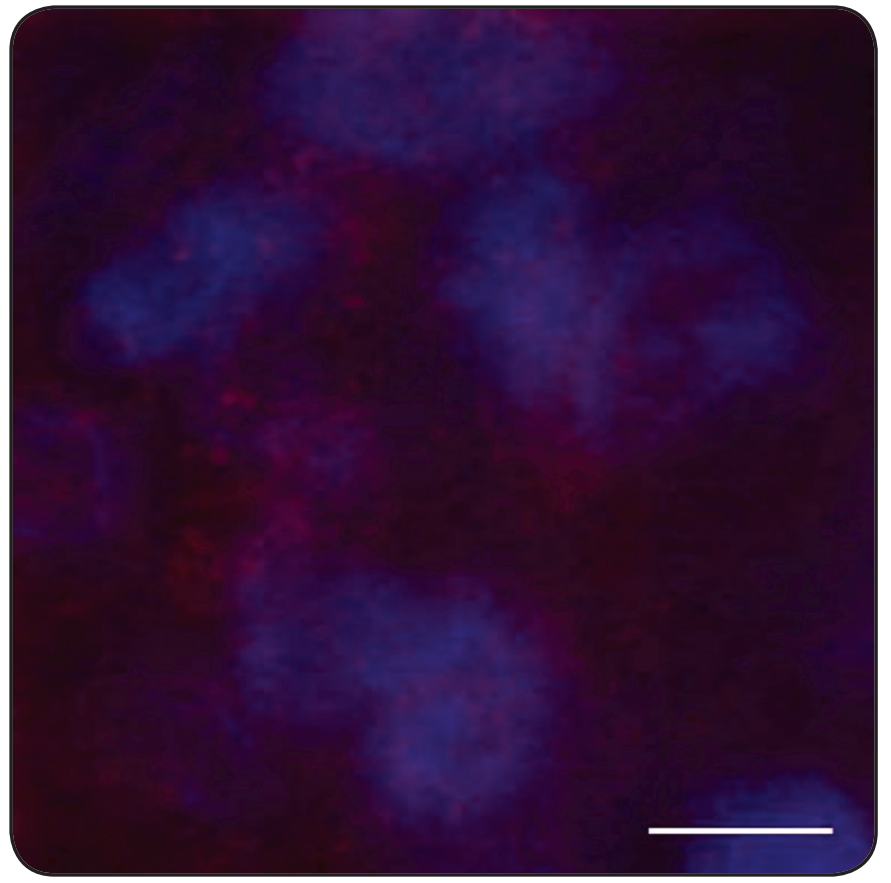

FIGURE 2 - Staining of Leishmania parasites in infected skin. A cellular exudative reaction lesion with macrophages and Leishmania parasites. Parasites are stained with antibodies conjugated to Alexa Fluor 546 (red), and nuclei are stained with DAPI (4',6-diamidino-2-phenylindole)(blue). Scale bar: $10 \mu \mathrm{m}$.

\section{DISCUSSION}

In this study, the patients were infected with L. braziliensis alone; notably, patients examined by Carvalho et al ${ }^{(4)}$ in HUJM/ UFMT, Cuiabá, Brazil were also infected by L. braziliensis alone, suggesting that this species is the most prevalent in different areas in Brazil.

ANXA1 has pleiotropic and pluripotent effects in several biological processes, including inflammation and tumorigenesis ${ }^{(19)(20)(23)}$. However, the role of ANXA1 in adaptive immunity is poorly defined. Published data indicate that ANXA1 expression is lower in lymphocytes than in neutrophils and monocytes ${ }^{(24)(25)}$, and imply that ANXA1 modulates T cell-mediated immune response ${ }^{(26)}$ by activating specific signaling pathways and suppressing transcription factors ${ }^{(26)(27)}$.

The host immune response elicited by Leishmania has been widely studied, and was shown to be extremely complex and variable $^{(11)(28)}$. However, the role of ANXA1 in this response is unknown. Our data demonstrate that skin macrophages from patients with cutaneous leishmaniasis express ANXA1 more abundantly than do macrophages from uninfected skin, major histocompatibility complex those observed in other leukocytes at steady state and during acute ${ }^{(29)}$ or chronic inflammation ${ }^{(30)}$. Abundant expression at infection sites also suggests that the protein may be involved in phagocytosis of parasites. Indeed, the literature shows that ANXA1 regulates phagocytosis, macrophage differentiation, and activation ${ }^{(20)(31)(32)(33)}$ by inducing the expression of CD40, CD54, CD80, CD84, major histocompatibility complex class II (MHCII), and CCR $7^{(33)}$. Finally, Collins et al ${ }^{(34)}$ detected ANXA1 in vacuoles containing L. mexicana, implying that the protein might facilitate vesicle fusion with endosomes.

The literature also suggests that ANXA1 in phagocytes facilitates clearance of apoptotic cells ${ }^{(32)}$. Indeed, macrophages in ANXA1-deficient mice have reduced capacity to clear apoptotic bodies ${ }^{(31)}$. Notably, Tzelepis et al ${ }^{(35)}$ reported that these mice are highly susceptible to Mycobacterium tuberculosis, and that ANXA1 expression is significantly downregulated in infected dendritic cells, suggesting that suppression of ANXA1 is a critical mechanism for immune evasion by Mycobacterium tuberculosis. In our patients, ANXA1 expression is more abundantly expressed in necrotic lesions than in cellular or granulomatous lesions, implying that expression in necrotic lesions is stimulated by the need to clear both parasites and necrotic tissue. Indeed, several studies have demonstrated that ANXA1 expression can be precisely calibrated depending on the stimulus, of which glucocorticoids $^{(36)}$ and tumor necrosis factor alpha $(\mathrm{TNF}-\alpha)^{(18)}$ are the most extensively characterized.

We found ANXA1 to be expressed in $\mathrm{CD}^{+}$and $\mathrm{CD} 8^{+} \mathrm{T}$ cells as well, suggesting that the protein is upregulated during the immunological response to Leishmania. T cells in cellular lesions express ANXA1 robustly, presumably due to widespread inflammation, as indicated by accumulation of lymphohistiocytic and plasmacytic infiltrate, edema, and absence of granuloma. ANXA1 has been described in the literature as a key regulator of T cell activation and migration to inflammatory sites ${ }^{(29)(30)(33)}$, and of signaling pathways (p38, ERK MAPK, Akt, and NF-kB) that control production of cytokines such as TNF- $\alpha$, INF- $\gamma$, IL2 , and IL-17(37) (38). ANXA1 also regulates the differentiation and proliferation of lymphocytes ${ }^{(18)}$. For instance, ANXA1 was recently demonstrated to regulate the differentiation of Th 0 cells into Th $1^{(33)}$, although Th2 cells predominate in ANXA1-deficient animals ${ }^{(37)}$. Finally, ANXA1 expression did not correlate with the age of the lesion, suggesting that expression might be regulated by pro-inflammatory mediators at inflamed sites, as has been reported ${ }^{(18)(36)}$.

Our study evaluates the differential ANXA1 expression in different histophatological lesions of patients with cutaneous leishmaniasis (CL). The results were very positive; however, all patients were infected with Leishmania brasiliensis. It is possible that other parasite species shows a different pattern of expression.

In summary, our data show for the first time that ANXA1 is differentially expressed in macrophages and $\mathrm{T}$ cells in lesions due to leishmaniasis, and expression is dependent on the histopathological characteristics of the lesion. We anticipate that future studies will further clarify the regulatory mechanism of cell action of ANXA1 during Leishmania infection. 


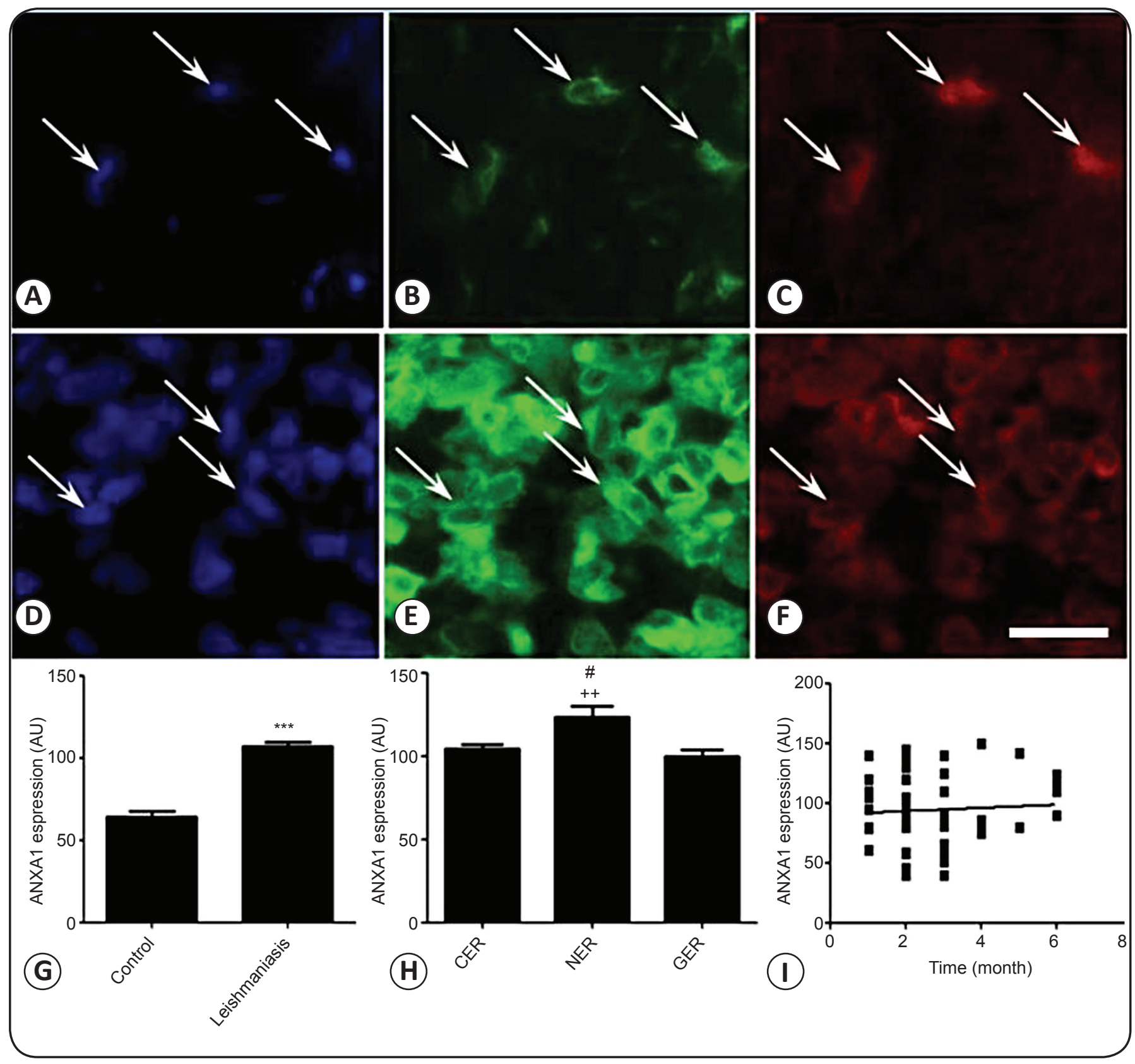

FIGURE 3 - ANXA1 expression in $\mathrm{CD163}^{+}$macrophages in Leishmania-infected skin. A-C: Basal ANXA1 expression in CD163 ${ }^{+}$ macrophages (arrows) in uninfected skin. D-F: Cellular exudative reaction lesion with $\mathrm{CD} 163^{+}$macrophages in lymphohistiocytic and plasmacytic infiltrate. A and D: Nuclei stained with DAPI. B and E: CD163 ${ }^{+}$macrophages expressing ANXA1 in the cytoplasm. $\mathrm{C}$ and F: Immunofluorescent staining of the macrophage marker CD163. G: ANXA1 expression in macrophages in uninfected and infected skin. H: ANXA1 expression in macrophages in necrotic (NER), cellular (CER), and granulomatous (GER) lesions. I: ANXA1 expression in $\mathrm{CD} 163^{+}$macrophages did not correlate with age of the lesion. ANXA1: annexin A1; CD: cluster of differentiation; DAPI: 4',6-diamidino-2-phenylindole; NER: necrotic exudative reaction; CER: cellular exudative reaction: GER: granulomatous exudative reaction. Statistical analysis as described in Methods: $* * * p<0.0001$ against uninfected skin. $++p<0.01$ against GER lesions. \#p $<0.05$ against CER lesions. Scale bar: $50 \mu \mathrm{m}$. 


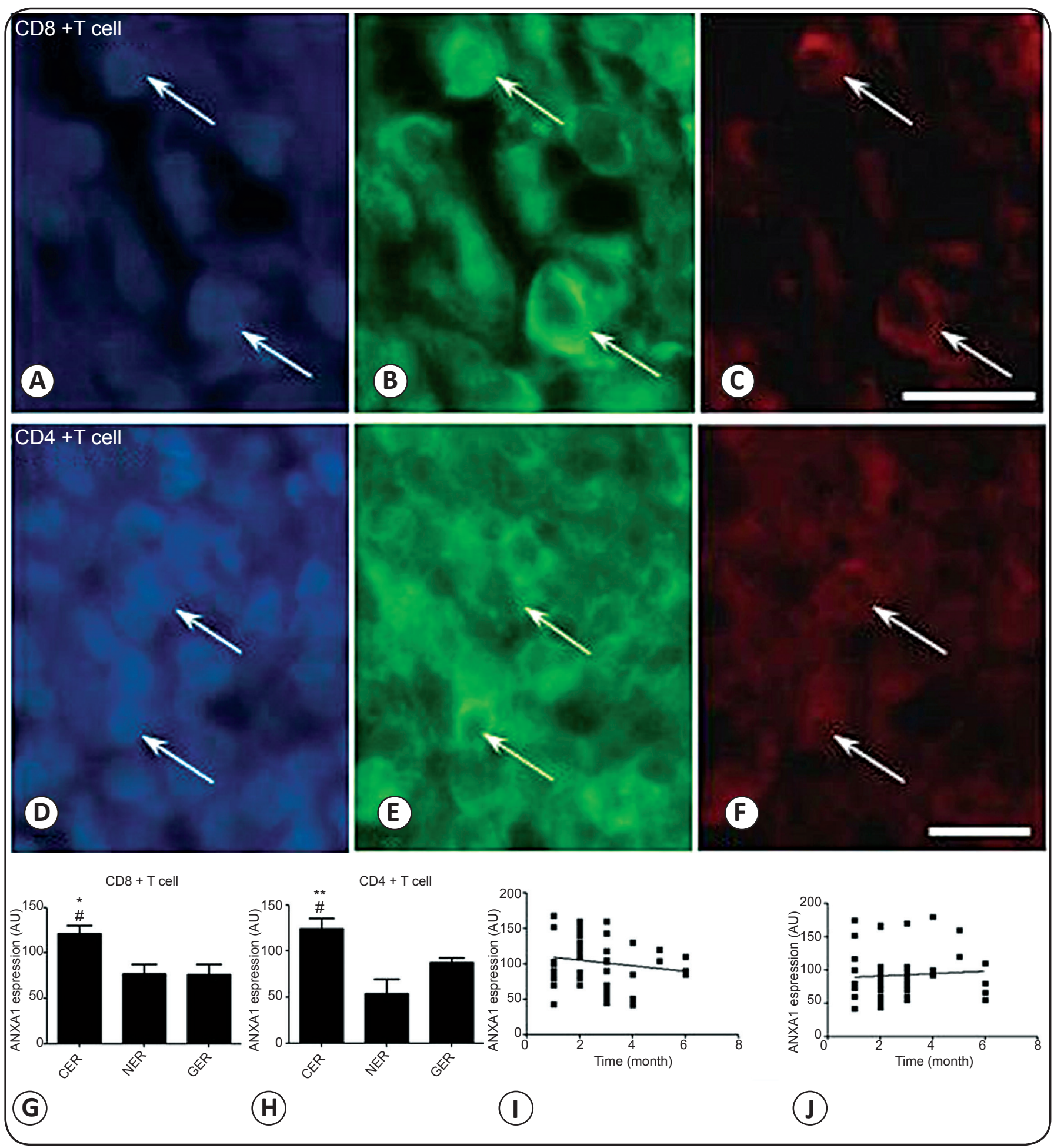

FIGURE 4 - ANXA1 expression in $\mathrm{CD4}^{+}$and $\mathrm{CD8}^{+} \mathrm{T}$ cells in Leishmania-infected skin. ANXA1 expression in (A-C) CD8 ${ }^{+}$and (D-F) $\mathrm{CD4}^{+} \mathrm{T}$ cells in the lymphohistiocytic and plasmacytic infiltrate of a cellular exudative lesion. A and D: Nuclei stained with DAPI. $B$ and $E$ : $T$ cells expressing ANXA1 in the cytoplasm. $C$ and F: Immunofluorescent staining of T cell markers CD8 and CD4. G and H: ANXA1 expression in cellular (CER), granulomatous (GER), and necrotic (NER) exudative reaction lesions. I and J: ANXA1 expression in $\mathrm{CD8}^{+}$and $\mathrm{CD4}^{+} \mathbf{T}$ cells did not correlate with age of lesion. ANXA1: annexin A1; CD4 ${ }^{+}$: cluster of differentiation $4^{+}$; CD8 $^{+}$: cluster of differentiation $8^{+}$; DAPI: 4',6-diamidino-2-phenylindole; CER: cellular exudative reaction; GER: granulomatous exudative reaction; NER: necrotic exudative reaction. Statistical analysis as described in Methods: *p $<0.05$; * $p<0.01$ against NER lesions. $\# p<0.05$ against CER lesions. Scale bar: $100 \mu \mathrm{m}$. 


\section{CONFLICT OF INTEREST}

The authors declare that there is no conflict of interest.

\section{FINANCIAL SUPPORT}

The work was supported by Research Support Foundation of Mato Grosso (Fundação de Amparo a Pesquisa de Mato Grosso), Protocol number 445778/2009 (EDITAL PPSUS/FAPEMAT number 006/2009). ASD and HALS were supported by the Brazilian National Council for Scientific and Technological Development (Conselho Nacional de Desenvolvimento Cientifico e Tecnológico; Grant number 303997/2011-7 to ASD, and Master scholarship number 132749/2013-0 to HALS).

\section{REFERENCES}

1. Ross R. Note on the bodies recently described by Leishman and Donovan. Br Med J 1903; 2:1261-1262.

2. Gontijo B, Carvalho MLR. American cutaneous leishmaniasis. Rev Soc Bras Med Trop 2003; 36:71-80.

3. Basano SA, Camargo LMA. Leishmaniose tegumentar americana: história, epidemiologia e perspectivas de controle. Rev Bras Epidemiol 2004; 7:328-337.

4. Carvalho MLR, Andrade ASR, Fontes CJF, Hueb M, Silva SO, Melo MN. Leishmania (Viannia) braziliensis is the prevalent species infecting patients with tegumentary leishmaniasis from Mato Grosso State, Brazil. Acta Tropica 2006; 98:277-285.

5. Pirmez C, Yamamura M, Uyemura K, Oliveira MP, Silva FC, Modlin RL. Cytokine patterns in the pathogenesis of human leishmaniasis. J Clin Invest 1993; 91:1390-1395.

6. Diaz NL, Arveláez FA, Zerpa O, Tapia FJ. Inducible nitric oxide synthase and cytokine pattern in lesions of patients with American cutaneous leishmaniasis. Clin Exp Dermatol 2006; 31:114-117.

7. Ehrchen JM, Roebrock K, Foell D, Nippe N, von Stebut E, Weiss JM, et al. Keratinocytes determine Th1 immunity during early experimental leishmaniasis. PLoS Pathog 2010; 6:e1000871.

8. Von Stebut E. Immunology of cutaneous leishmaniasis: the role of mast cells, phagocytes and dendritic cells for protective immunity. Eur J Dermatol 2007; 17:115-122.

9. Baldwin T, Sakthianandeswaren A, Curtis JM, Kumar B, Smyth GK, Foote SJ, et al. Wound healing response is a major contributor to the severity of cutaneous leishmaniasis in the ear model of infection. Parasite Immunol 2007; 29:501-513.

10. Silveira FT, Lainson R, Corbett CEP. Clinical and immunopathological spectrum of American cutaneous leishmaniasis with special reference to the disease in Amazonian Brazil. Mem Inst Oswaldo Cruz 2004; 99:239-251.

11. Hartley MA, Kohl K, Ronet C, Fasel N. The therapeutic potential of immune cross-talk in leishmaniasis. Clin Microbiol Infect 2013; 19:119-130.

12. Alexander J, Brombacher F. T helper1/t helper2 cells and resistance/susceptibility to Leishmania infection: is this paradigm still relevant? Front Immunol 2012; 3:80.

13. Silveira FT, Lainson R, De Castro Gomes CM, Laurenti MD, Corbett CE. Immunopathogenic competences of Leishmania (V.) braziliensis and L. (L.) amazonensis in American cutaneous leishmaniasis. Parasite Immunol 2009; 31:423-431.
14. Cardoso TM, Machado A, Costa DL, Carvalho LP, Queiroz A, Machado P, et al.. Protective and pathological functions of CD8+ $\mathrm{T}$ cells in Leishmania braziliensis infection. Infect Immun 2015; 83:898-906.

15. Pereira-Carvalho R, Mendes-Aguiar CO, Oliveira-Neto MP, Covas CJ, Bertho AL, Da-Cruz AM, et al. Leishmania braziliensisreactive $\mathrm{T}$ cells are down-regulated in long-term cured cutaneous leishmaniasis, but the renewal capacity of $\mathrm{T}$ effector memory compartments is preserved. PLoS One 2013; 8:e81529.

16. Perretti M, Christian H, Wheller SK. Annexin 1 is stored within gelatinase granules of human neutrophil and mobilized on the cell surface upon adhesion but not phagocytosis. Cell Biol Int 2000; 24:163-174.

17. Perretti M, Felicity N, Gavins FN. Annexin 1: an endogenous antiinflammatory. News Physiol Sci 2003; 18:60-64.

18. Kamal AM, Flower RJ, Perretti M. An overview of the effects of annexin 1 on cells involved in the inflammatory process. Mem Inst Oswaldo Cruz 2005; 100:39-47.

19. Perretti M, D'Acquisto F. Annexin A1 and glucocorticoids as effectors of the resolution of inflammation. Nat Rev Immunol 2009; 9:62-70.

20. Blume KE, Soeroes S, Keppeler H, Stevanovic S, Kretschmer D, Rautenberg M, et al. Cleavage of annexin A1 by ADAM10 during secondary necrosis generates a monocytic "find-me" signal. J Immunol 2012; 188:135-145.

21. Magalhães AV, Moraes MAP, Raick AN, Llanos-Cuentas A, Costa JML, Cuba CC, et al. Histopatologia da leishmaniose tegumentar americana por Leishmania braziliensis braziliensis. Classificação histopatológica. Rev Inst Med Trop Sao Paulo 1986; 28:421-430.

22. Schonian G, Nasereddin A, Dinse N, Schweynoch C, Schallig HDFH, Presber W, et al. PCR diagnosis and characterization of Leishmania in local and imported clinical samples. Diagn Microbiol Infect Dis 2003; 47:349-358.

23. D'Acquisto F, Perretti M, Flower RJ. Annexin-A1: a pivotal regulator of the innate and adaptative immune systems. Br J Pharmacol 2008; 155:152-169.

24. Morand EF, Hutchinson P, Hargreaves A, Goulding NJ, Boyce NW, Holdsworth SR. Detection of intracellular lipocortin 1 in human leukocyte subsets. Clin Immunol Immunopathol 1995; 76:195-202.

25. Perretti M, Flower RJ. Measurement of lipocortin 1 levels in murine peripheral blood leukocytes by flow cytometry: modulation by glucocorticoids and inflammation. Br J Pharmacol 1996; 118:605-610.

26. Patel HB, Kornerup KN, Sampaio ALF, D'Acquisto F, Seed MP, Girol AP, et al. The impact of endogenous annexin A1 on glucocorticoid control of inflammatory arthritis. Ann Rheum Dis 2012; 71:1872-1880.

27. Weyd H, Abeler-Dörner L, Linke B, Mahr A, Jahndel V, Pfrang $\mathrm{S}$, et al. Annexin A1 on the Surface of Early Apoptotic Cells Suppresses CD8+ T Cell Immunity. PLoS One 2013; 8:e62449.

28. Noben-trauth N, Paul WE, Sacks DL. IL-4- and IL-4 receptordeficient $\mathrm{BALB} / \mathrm{c}$ mice reveal differences in susceptibility to Leishmania major parasite substrains. J Immunol 1999; 162:6132-6140.

29. Gibbs L, Carollo MG; Damazo AS, Oliani SM, Perretti M. Time-dependent expression of leukocyte-associated annexin 1 in a model of chronic granulomatous inflammation. Inflamm Res 2001; 51:300-306.

30. Damazo AS, Yona S, Flower RJ, Perretti M, Oliani SM. Spatial and temporal profiles for anti-inflammatory gene expression in leukocytes during a resolving model of peritonitis. J Immunol 2006; 176:4410-4418. 
31. Dalli J, Jones CP, Cavalcanti DM, Farsky SH, Perretti M, Rankin SM. Annexin A1 regulates neutrophil clearance by macrophages in the mouse bone marrow. FASEB J 2012; 26:387-396.

32. Yang YH, Morand EF, Getting SJ, Paul-Clark M, Liu DL, Yona S, et al. Modulation of inflammation and response to dexamethasone by Annexin 1 in antigen-induced arthritis. Arthritis Rheum 2004; 50:976-984.

33. Huggins A, Paschalidis N, Flower RJ, Perretti M, D'Acquisto F. Annexin-1-deficient dendritic cells acquire a mature phenotype during differentiation. FASEB J 2009; 23:985-996.

34. Collins HL, Schaible UE, Ernst JD, Russell DG. Transfer of phagocytosed particles to the parasitophorous vacuole of Leishmania mexicana is a transient phenomenon preceding the acquisition of annexin I by the phagosome. J Cell Sci 1997; 110:191-200.
35. Tzelepis F, Verway M, Daoud J, Gillard J, Hassani-Ardakani K, Dunn J, et al. Annexin1 regulates DC efferocytosis and crosspresentation during Mycobacterium tuberculosis infection. J Clin Invest 2015; 125:752-768.

36. Perretti M, D'Acquisto F. Novel Aspects of Annexin 1 and Glucocorticoid Biology: Intersection with Nitric Oxide and the Lipoxin Receptor. Inflamm Allergy Drug Targets 2006; 5:107-114.

37. Yang YH, Song W, Deane JA, Kao W, Ooi JD, Ngo D, et al. Deficiency of Annexin A1 in CD4+ T cells exacerbates T celldependent inflammation. The Journal of Immunology 2013; 190:997-1007.

38. D'Acquisto F, Paschalidis N, Sampaio AL, Merghani A, Flower RJ, Perretti M. Impaired T cell activation and increased Th2 lineage commitment in Annexin-1-deficient T cells. Eur J Immunol 2007; 37:3131-3142. 